The ethics of interpretation: the signifying chain from field to analysis

(Forthcoming in Discourse 29(1), which will be published in March 2008)

Claudia Lapping

Institute of Education

20 Bedford Way

London WC1H OAL

e-mail: c.lapping@ioe.ac.uk

Claudia Lapping completed her PhD in 2004, at the Institute of Education, University of London, where she is currently working as a lecturer in Education. 


\title{
The ethics of interpretation: the signifying chain from field to analysis
}

\begin{abstract}
This paper attempts to describe the relationship between the embodied practice of fieldwork and the written articulation of this experience. Starting from Valerie Hey's conceptualisation of 'rapport' as form of 'intersubjective synergy', a moment of recognition of similarity within difference - similar in structure to Laclau and Moufffe's conceptualization of hegemony - the paper explores how we can understand these moments of recognition as positioned within a complex web of signifying chains that interlink social, psychic and linguistic means of representation. Laclau and Mouffe's logics of equivalence and difference and Lacan's account of the production of meaning through metaphor and metonymy provide a theoretical language through which to explore chains of meaning in two fragments of data drawn from a study comparing disciplines and institutions in higher education. My argument is that an awareness of these processes of production of meaning is necessary to the development of an ethical mode of interpretation.
\end{abstract}

Key words: metaphor, metonymy, chain of signifiers, contingency, hegemony, 'rapport'

From 'rapport' to hegemony

This paper intertwines three strands of argument: an interpretation of my positioning within interactions with one of my research participants, a theoretical argument about the production of meaning, and, following from this, an articulation of what it might mean to take an ethical position as a researcher. The paper was initially written in response to a very specific anxiety concerning the effects of my research on Duncan ${ }^{1}$, one of the tutors who participated in my study. I felt there had been moments within the research relationship when ambiguities in my position, and my clumsiness in dealing with these ambiguities, had allowed misunderstandings to develop about the nature of the research and the way in which I would analyse Duncan's practice. I was also anxious about our final communication, which had left unanswered questions about his response to sections of the analysis that I had sent him². Eventually, I selected two fragments of interaction between myself and Duncan to analyse in relation to the ethics of the research relationship. I situated my interpretation of these extract within a broader theoretical understanding of the discursive mechanisms that constitute inter-subjective relations between researcher and researched. This paper, then, was written in an attempt to come to terms with some unsettled feelings about my research practice. To do this, it constructs a theoretical framework that begins to articulate an ethics of interpretation that clarifies the position of the researcher in relation to research participants, analysis, and writing.

\footnotetext{
${ }_{1}^{1}$ Not his real name.

${ }^{2}$ An account of the final communication between Duncan and myself is presented in an addendum to the paper.
} 
There is, I think, a useful distinction to be made between my initial response to my anxiety and my later theorization of my position. My initial concerns were about methods: what I should or shouldn't have said to my participants at various stages of the research. These concerns correlate with recent discussions in the research methods literature articulating the ethical complexities of 'rapport' and 'informed consent' (Duncombe and Jessop, 2002, Finch 1984, Birch and Miller, 2002). However, such discussions tend to be contextualized within specific research projects and do not address broader theoretical questions about the objectifying and political potentials of research, and how these may have connotations for the construction of an ethical position within fieldwork and analysis. In writing this paper I wanted to move beyond a focus on 'methods' to develop a more abstracted conceptualization of ethical relations. This shift was mediated in part through the work of Valerie Hey.

Hey has articulated her theorisation of the politics of research through a reconceptualisation of 'rapport' as 'a momentarily achieved (fragile) form of intersubjective synergy that is produced with and against the force of the binary norms that marshal us into our respective places' (2000, p. 165). Arguing against criticisms of the concept that assume 'rapport' connotes a naïve or mystical authentic connection, Hey suggests that there is a need to recognize 'the psychic economy of 'rapport", not as a 'guarantor of truth', but as a proper theorization of the embodied experience of participating in fieldwork (ibid, p. 173). For me, Hey's work provided a theoretical link from relatively limited methodological accounts of 'rapport' to theoretical conceptualisations of hegemony and the discursive production of subjectivity. Her work also constitutes an instance of written ethnography that contrasts in significant ways with the accounts of data in my own writing.

Hey develops her argument through an autobiographical account of her relationship to the working class and middle class young women who were her research participants in her study of girls' friendships (see Hey, 1997). The use of autobiography allows Hey to codify the moments of similarity and difference that constituted her relationship with these young women: she recognized, from her own childhood, the discourses of respectability that positioned her working class participants in relation to both school and domesticity, but their contrasting responses to these discourses had enacted different aspirations. While Hey had imagined escape through education, her participants' fantasies foregrounded their sexuality as a means of release from the constraints of their current position. Hey disentangles these aspects of her identification with her participants, explaining:

I have never felt the force field of research relations as singular monolithic states of 'rapport'/'difference'. (p. 163)

Understood in this way, 'rapport' requires delicate analysis of the context of the researcher's changing and unstable identifications with participants, and their developing understanding of the research setting. It should also be understood, 
as Hey suggests, as uneven, transitory and fragile, offering no lasting or certain answers to difficult questions of interpretation. Thus the question facing an ethical researcher is no longer about how or whether we might be able to establish 'rapport', nor about whether 'rapport', once established, either recognizes or exploits marginal subjectivities, but rather about the way in which a more nuanced understanding of the different textures and intensities of the research relationship might contribute to our understanding of both the objectifying and the political potentials of research.

My argument in this paper concerns these potentials of research, the way the process of analysis articulates and fixes the meaning of ambiguous and transient moments within the research relationship, and the ongoing political and ethical effects of these articulated meanings. The question Valerie Hey raises is whether the process of interpretation can codify and stabilize these significations to form the basis of a politically engaged research practice. She argues:

my metaphor for 'rapport' compares it to the sought after hegemony of political alliances - the temporary contract between people that holds both sameness and difference in play and thus allows for action and representation (p. 176).

This metaphor can be reframed in the language of Ernesto Laclau and Chantal Mouffe's account of hegemony and articulatory processes (Laclau and Mouffe, 2001).

Hegemony: the articulation of equivalence within difference

In their preface to the second edition of Hegemony and Socialist Strategy, Laclau and Mouffe describe their work as an attempt to close 'an increasing gap between the realities of contemporary capitalism and what Marxism could legitimately subsume under its own categories' (2001, p. viii). Their strategy for achieving this, they suggest, is to 'reactivate' Marxist theory by drawing attention to the contingency of the original concepts and raising questions about the continuities and discontinuities between the context in which the theory was developed and new problems raised in the development of contemporary capitalism ( $p$. viii-ix). As they point out, this change in the context and categories of analysis 'leads also to a new ontological paradigm' (ibid, p. $x$ ) constituted in their account of articulatory processes. Their theory of articulation, then, is formulated to express the contingency of discursive structures and draws explicitly on Lacanian psychoanalytic theory, which points to a lack in the structure of language. The basis of this lack, for Lacan, is the relationship between the real and symbolic orders. The Lacanian real, that which is beyond language, can never be (fully) represented within the discursive structures of the symbolic order. Articulation, then, is opposed to mediation, which, for Laclau and Mouffe, suggests a direct or necessary link between a transcendent totality and symbolized social organization. In contrast to this direct representation, an articulatory practice modifies the elements of the real within contingently organized discursive structures. Since the real can never be fully represented, the articulatory process is always incomplete: there are always gaps within 
discursive structures. These gaps are the space of politics, or the potential for change in social relations.

Laclau and Mouffe's central category for political analysis, the concept of hegemony, can be used to describe the emergence of individual interpretations and their role in unifying and (partially) fixing meanings in relation to a signifying system, in a way that is analogous to Hey's account of 'rapport'. This is, for me, most clearly explained by Laclau in Emancipations, when he describes the function of hegemony in establishing a link between a dispersed set of differentiated demands:

The meaning (the signified) of all concrete struggles appears, right from the beginning, internally divided. The concrete aim of the struggle is not only that aim in its concreteness; it also signifies opposition to the system. The first signified establishes the differential character of that demand or mobilization vis-à-vis all other demands or mobilizations. The second signified establishes the equivalence of all these demands in their common opposition to the system. As we can see, any concrete struggle is dominated by this contradictory movement that simultaneously asserts and abolishes its own singularity. (Laclau, 1996, p. 41)

Laclau thus suggests that what is signified in any moment of articulation always has two aspects, one that relates to the particular instance of experience, and one that expresses how differing instances share a relationship of opposition to an existing linguistic or symbolic system. Valerie Hey's example of the ambiguities of 'rapport' within her research can be used to illustrate this dual role of the signifier as bringing together signifieds as same but different. What Laclau describes as 'the first signified', refers to the concrete differences between any two struggles. In Hey's example this is instantiated in the differences between her experience of working class girlhood and that of her participants. While Hey sought to achieve the fantasy of respectability through studious, desexualized educational success, her participants sought the same end through alternative means: Hey describes how 'Carol' represents herself as a heroine of heterosexual romance (2000, p. 166). While the 'first signified' articulates this difference in their experience, the 'second signified' 'establishes the equivalence of all these demands in their common opposition to the system'. What Hey's research articulates is a commonality in the dispersed experiences of working class young women that is their relation to a hegemonic discourse of respectability. However, there are two different moments of articulation of this commonality: the first is the embodied, empathetic understanding itself, that may remain scarcely more than a transiently recognized, inchoate experience; the second is the fuller articulation of this moment within Hey's writing, which both transforms the experience, and constitutes its signifying position within the symbolic practices of educational research literature.

These two different moments, one a partial recognition and one a more explicit articulation, can also be described in terms of Laclau and Mouffe's distinction 
between floating signifiers and (partially) fixed or hegemonic signifiers. Laclau describes a floating signifier as ambiguous to the extent that 'either an overdetermination or an underdetermination of signifieds prevents it from being fully fixed' (1996, p. 36). The concept of a floating signifier thus foregrounds the incomplete aspect to any articulation of meaning. The concept of fixed or hegemonic signifiers, in contrast, foregrounds the political effectivity of signification:

Any discourse is constituted as an attempt to dominate the field of discursivity, to arrest the flow of differences, to construct a centre. We will call the privileged discursive points of this partial fixation, nodal points. (Laclau and Mouffe, 2001, p. 112)

Nodal points, 'privileged signifiers that fix the meaning of a signifying chain' (ibid, p. 112), not only establish equivalences between dispersed demands, or experiences, but also organize relations between signifiers within the discursive field around this equivalence.

The unarticulated, or barely articulated recognition of 'rapport' within the embodied practice of fieldwork constitutes, perhaps, a radically underdetermined floating signifier. The written articulation of this experience is a move towards the partial fixing of meaning in order to reorganize the existing discursive field. This paper is an attempt to describe this transformation of embodied, inchoate experience, by identifying some of the processes of production of meaning in the development of the analysis. These process, I will suggest, can be described in terms of a Lacanian understanding of metaphor and metonymy as the two 'sides' through which the signifier produces the signified (Lacan, 1989, p. 177), or, alternatively, in Laclau and Mouffe's reworking of these concepts in their account of the logics of equivalence and difference. There are also similarities between this work and Walkerdine's use of the concept of metaphor to describe the way children establish and move between discursive contexts in primary classrooms $(1982,1988)$. Walkerdine suggests the way in which the metaphorical aspect of mathematical language gains mastery through the suppression of the personal features of the subject (1988, p. 186). What I am describing here is the way in which academic analyses, and the production of meanings more generally, enact similar suppressions, excluding important specificities embedded within the experience of the field.

Metaphor and metonymy as constitutive of the signifying chain

It might be possible to think of the embedded experience of the field as the (lacanian) real and the process of transcription and analysis as a means of symbolising and simultaneously excluding aspects of the real. Alternatively, you might see the interactions in the field as an already symbolic representation of the unconscious of researcher and participants. Either way, there is a symbolic chain that links the diverse levels of unconscious, field and analysis. This chain can be described as working through the mechanisms of metaphor and metonymy. 
Metaphor and metonymy in their linguistic sense can, perhaps, be relatively simply defined. While metonymy is based on a relationship of contiguity, the word for a part used to represent a whole ('sail' for 'ship', 'throne' for 'kingdom'), metaphor constitutes a relationship of association through the substitution of one word for another. Even in their 'purely' linguistic sense, though, the distinction between the two may not always be unproblematic (metonym can be thought of as a particular type of metaphor) so when the terms are used to describe relations that move beyond the 'purely' linguistic the notion of a direct translation is not necessarily productive. Lacan's use of metaphor and metonymy to reconceptualise Freud's account of the production of meaning in the dream-work through the mechanisms of condensation and displacement is also an indirect translation of the terms, as Lacan suggests:

What distinguishes these two mechanisms, which play such a privileged role in the dream-work, from their homologous function in discourse? Nothing, except a condition imposed upon the signifying material, called Rucksicht auf Darstellbarkeit, which must be translated by 'consideration of the means of representation'. (Lacan, 1989, p. 177)

The 'means of representation' in a dream are not simply words (see RaglandSullivan, 1986, p. 235), and so the interpretation of individual instances of images that work to condense or displace meaning within dreams as either metaphor or metonym, and the ensuing development of these concepts, will depend on the interpretive framework of the theorist (see, for example, Stavrakakis, 1999, p. 59, on Jakobson and Lacan's contrasting interpretations). What Lacan's recontextualisation suggests is the potential productivity of the structure of metaphor and metonymy for understanding the production of meaning through various means of representation.

The relation Lacan is constructing through his reconceptualisation of the dreamwork is one that foregrounds both the link between the unconscious and language, and, as in his famous formulation, the language-like structuring of the unconscious. He does this by identifying the ways in which mechanisms that are analogous to metaphor and metonymy link manifest and latent dream content, conscious and unconscious, through the processes of condensation and displacement (Lacan, 1989, Ragland-Sullivan, 1986). As Ragland-Sullivan puts it:

Although metaphor does, indeed, emerge from two signifiers (in Lacan's sense), this occurs within a signifying chain. One signifier is substituted in a Saussurean chain of signs, but the word or image substituted does not merely disappear on being transformed. It remains present (repressed or signified) by its metonymic connection to the chain of meaning itself ... The supplanted signifier, in other words, falls from the level of consciousness to the level of unconsciousness, where it acts as a kind of latent unconscious signifier grafted onto an unconscious chain of associations. (ibid, p. 234) 
Thus, Lacan suggests not only that metaphor and metonymy offer useful structures for describing the production of meaning, but also that these structures can help us to understand the way meanings are constituted across different levels or 'means' of representation. This can then be translated to construct a description of the way substitutions are made in our analysis of field data, which replicates the way a 'supplanted signifier' from the field may, adapting RaglandSullivan's phrase, 'fall from the level of analysis to the level of the field'.

A similar translation of the mechanisms of metaphor and metonymy is articulated in Laclau and Mouffe's logics of difference and of equivalence. It should already be apparent that hegemony, the articulation of equivalence within difference, has the structure of metonymy: the equivalence thus articulated takes a part to represent a whole. The distinction they make between the logics of difference and equivalence, though, constitutes a refinement of this structure that parallels Lacan's contrast between metonymic connections and metaphorical substitutions. For Laclau and Mouffe, the metonymic structure allows the social space to support differences, while the break brought about through metaphorical substitution enforces an equivalence that eliminates the differential features of an object:

If all the differential features of an object have become equivalent, it is impossible to express anything positive concerning that object; this can only imply that through the equivalence something is expressed which the object is not ... Hence the ambiguity penetrating every relation of equivalence: two terms, to be equivalent, must be different - otherwise, there would be a simple identity. On the other hand, the equivalence exists only through the act of subverting the differential character of those terms. (2001, p. 128)

The metaphorical substitution, as suggested by Lacan, forces the individualizing features of the substituted object outside the system. But, as Gasche points out, this excluded signifier remains within the system to the extent that it is signified as that which the system is not:

The logic of equivalence thus leads to the formation of signifieds that imply the system as a whole, and that, paradoxically, signify (indirectly, negatively) the excluded outside or the beyond of the system. (2004, p. 25)

Laclau and Mouffe's categories, it seems to me, retain fluidity in the distinction between metonymy and metaphor, difference and equivalence. The logic of difference foregrounds a similarity within identities, without excluding the positivity of those identities from the system. The logic of equivalence performs a more radical substitution, in which, as Laclau suggests, difference is 'almost entirely' eradicated:

It is only by privileging the dimension of equivalence to the point that its differential nature is almost entirely obliterated - that is emptying it of its differential nature - that the system can signify itself as a totality. (Laclau, 1996, p. 39) 
What Laclau's 'almost entirely' retains is a sense of the openness of the system, which is also relevant to my consideration of the ethics of interpretation. The questions I am asking in the following sections relate to this possibility of openness. To what extent does my analysis constitute an obliteration of specificities and differences that inhere in my data? To what extent do we attempt to constitute argument as a coherent totality that excludes difference? And in what ways may we able to maintain the openness of the system within our interpretations? Whilst always remembering that the purpose of analysis is also to 'arrest the flow of differences' (Laclau and Mouffe, 2001, p. 112), to construct and attempt to fix new fields of meaning.

\section{Fragment 1: 'rapport' as the articulation of equivalence within difference}

The extracts I am using are taken from my $\mathrm{PhD}$ research which explored the positioning of students on undergraduate courses. The analysis developed a description of student positions as constituted in relation to the discipline they were studying, the institution in which they were studying, and hegemonic codes of masculinity and femininity (see Lapping, 2004, 2005). Each of these discursive fields was conceputalised as an incomplete identity that then had to be objectified within the analysis. The data that formed the basis of this objectification were a combination of classroom observations and interviews: I participated in a series of sessions on two modules in American Literature and two in Political Thought, videoed the classes, and interviewed students and tutors about the discussions that I had observed. Duncan was one of the American Literature tutors whose classes I observed.

In preparation for my interview with Duncan I had carried out a preliminary analysis of the transcripts and identified extracts for us to discuss. One significant aspect of this process was the development of an explicit objectification of the disciplines. So, one of the purposes of discussing extracts from the transcripts with Duncan was to clarify and perhaps confirm my initial analysis of the nature of his subject, and of literary studies more broadly.

Contemporary literary studies is a multi-methodological field that incorporates historical and sociological approaches as well as the close textual analysis more traditionally associated with the discipline. I was interested in identifying the way in which complex readings that combined these approaches and readings that presented relatively simplistic deployments of sociological categories were both legitimized strategies for doing literary studies within the classroom. For example, in analyzing the presentation of 'race' within a text, some students would refer to metaphorical implications of language and plotting and the relationship between these textual features, while others would start from the assumption that the repetition of stereotypes is wrong, and use the identification of stereotypes to develop a political critique of an author and/or text. Both American Literature tutors in the study tended to respond to the less textualised readings by offering prompts, or questions encouraging students to develop a more reflective 
approach to the text. However, in the North University session on 'Benito Cereno', a disturbing story by Herman Melville that explicitly deploys dangerous, racialised imagery in order to evoke a racist ideology, Duncan, the tutor, had presented two possible readings, correlating to the two approaches described above. This contrasted with his position in the session on Moby Dick, which he had presented as a less ambiguous example of an anti-slavery or anti-racist text.

In the interview I showed Duncan an extract from the session on Moby Dick where one student, Dean, had suggested that the association of savagery with a Polynesian character, Queequeg, within the book undermined its progressive intentions. Another student had responded by referring to examples of savagery in the white characters in the novel, arguing that the depiction of the relationship between 'race' and savagery was more complex than Dean was suggesting. Duncan's initial response to the extract was that 'Dean is saying something that's a bit crude, I think, about savagery and how that links to violence'. He commented that the second student 'says something that's much more like something that I would say, and moves the conversation onto another level'.

At this point I introduced my observation that his interpretation of Melville had seemed much more ambiguous in the session on 'Benito Cereno' than in the session on Moby Dick. Duncan acknowledged my point, and then talked about the implications it might have for his reading of the novel:

$\mathrm{CL}$ : What about, there's a similar type of discussion that happens in the 'Benito Cereno' session where you get one of the students, Jonathan, I think, picking out the sort of, what could be seen as racist imagery around the animalization of black women, and there were two readings again. And you were actually kind of, I thought, trying to maintain the ambiguity. And it's less so here. Do you think that Dean here is in the sort of Jonathan sort of position. He's reading it in this kind of 'is this text racist' kind of way.

Duncan: Maybe.

$\mathrm{CL}$ : Which you were slightly more open to in terms of Benito Cereno than here.

Duncan: That's probably right. I'm glad you said that because I hadn't thought about that, but immediately I think it's right, that I was teaching Moby Dick in a more utopian way, whereas I might be rather more sensible in thinking that Benito Cereno was actually contaminated by the same racial thinking that it critiques ... I think a more nuanced reading of Moby Dick is one that says, yes, as well as critiquing racial thinking it does implement racial thinking, and I'm sure that's closer to the sort of ultimate position one might want to have about the text than saying that this is Melville in a very prescient way deconstructing racial thinking, because I don't think that's the case.

Embedded within the moment of fieldwork, I experienced Duncan's response as a gratifying recognition of my perceptive analysis of his practice. His words are explicitly affirming 'I'm glad you said that', and he then goes on to incorporate my 
observation into his own interpretation, suggesting 'a more nuanced reading of Moby Dick is one that says, yes, as well as critiquing racial thinking it does implement racial thinking'. This interpretation depends on, recognizes and incorporates my words, and thus momentarily unifies our positions. However, interpreted in relation to a conception of 'rapport' as an articulation of equivalence within difference, what is going on is more complex. While it is certainly the case that a particular understanding is articulated between us in this exchange, this same shared interpretation in fact belongs to two very different interpretive frames: I was interested in a sociological objectification of literary studies while Duncan was interested in a nuanced critical reading of Moby Dick. Nevertheless, these contrasting interests are articulated through the same recognition of the significance of Duncan's two different presentations of Melville.

What we have here, in extreme microcosm, is the articulation of a hegemony that unifies our separate interests under one signifier. This interpretation, again, has analogies to Hey's account of her 'rapport' with her young working class participants. In both cases there is a truth to the moment of 'rapport', which expresses a shared signifying position in relation to a symbolic system, and in both cases this shared signifying position has potential effects, either within or beyond the research process.

However, we can be more precise about some of these effects. This signifying moment constitutes a link in at least two distinct signifying chains. There is, firstly, the constitution of the meaning of our relationship, the relationship between researcher and researched. Our shared interpretation pervades our relationship during my research, such that we will, perhaps, continue to feel a sense of joint, collaborative enterprise and to assume some common understanding as to my purposes and possible analysis. This set of meanings has ethical implications in so far as it affects both what the participant reveals to the researcher and their expectations about the nature of the analysis. The second signifying chain constitutes precisely this process of analysis and writing: the moves I make as I weave the conversation from the interview into the argument of my doctoral thesis. This is where a certain violence is done to the data, as some meanings are privileged in the substitution of linear text for the richness of the data, and the 'supplanted signifiers', using Ragland-Sullivan's image, 'fall' from the analysis back into field. So, in the written analysis in my thesis, Duncan's words were used to support my objectification of literary studies as a multi-methodological discipline by demonstrating how, in the class on Benito Cereno:

Duncan explicitly set out to present the two contrasting ways of reading as providing equally viable interpretations of the text. (Lapping, 2004, p. 183)

The phrase 'explicitly set out' rearticulates Duncan's reflections on his approach to 'Benito Cereno' as a more direct concern with teaching than was perhaps evident in his words. I did not, in contrast, explicitly rearticulate his more literary interest in developing 'a more nuanced reading of Moby Dick' within the thesis. 
Arguably, this supplanted signifier remains in the 'unconscious' of the project, and may return to haunt any ethical complacency on the part of the researcher.

Laclau and Mouffe's logics of difference and equivalence may also be useful here, and may help to clarify a contrast between Hey's written analysis and my own. Hey's ethnographic account does not submerge the features of the differential identities of herself and her subjects, but incorporates their contrasting responses to the constraints of family and class. My account in my thesis said nothing about Duncan's literary interests. Thus Hey's hegemonising is closer to a logic of difference, while mine is, in comparison, closer to a logic of equivalence. The significance of an instance of 'rapport', then, is not fixed within the field, but within the analysis.

The constitution of a moment of 'rapport' within a logic of either difference or equivalence may, then, be better understood as a retroactive effect of the chain of signifiers. Zizek provides a useful account of this retroactive production of meaning. He suggests that relationships within the ongoing flow of signfiers only become fixed when a particular signifier emerges as a centre, a nodal point, in relation to which the meaning of other signifiers can be stabilized. However, where this privileged signifier is going to emerge, and in what form, is historically contingent. Thus, 'the effect of meaning is always produced backwards, apres coup':

Signifiers which are still in a 'floating' state - whose signification is not yet fixed follow one another. Then, at a certain point - precisely the point at which the intention pierces the signifier's chain, traverses it - some signifier fixes retroactively the meaning of the chain, sews the meaning to the signifier halts the slide of meaning ... [I]nstead of the linear, immanent, necessary progression according to which meaning unfolds itself from some initial kernel, we have a radically contingent process of retroactive production of meaning. (Zizek, 1989, pp. $101-102)$

There was a contingency to my interpretation of my interview with Duncan, and my analysis could have reinforced the positivity of his identity, as well as the positivity of the argument of my thesis. It was only my act of writing the interpretation that constituted, retrospectively, the point where 'intention pierces the signifier's chain', halted the flow of signifiers, and retroactively constituted the meaning of the interaction, excluding the differential features of Duncan's position. There was a similar contingency to Hey's interpretation of the moments of recognition she describes from her fieldwork. The retroactive work of the signifying chain, and thus the establishment of signifiers as floating or fixed, is, to some extent, overdetermined by the existing discursive field, but within the microcontexts of academic research, the subjective intention of the researcher is a significant contingency.

Fragment 2: metaphor and rupture in subjective identities 
I am using a second extract from the same interview with Duncan to explore the structure of metaphor as a substitution that constructs an implicit comparison between subjects (Ragland-Sullivan, 1986, p. 233). More specifically, I am going to interpret a series of interventions I made in the interview as substitutions connoting a shift in my subjective position from researcher, to participant, to educator. These shifts in my interventions, I will suggest, cover over a rupture within my own subjectivity and also in my relationship with Duncan, my research participant.

The ambiguities in my position are apparent in the following exchange, where Duncan introduced the topic of group work:

Duncan: ... I do a lot of group work, as you know, because the classes are so big that it can be the only way to get everyone to actually do some work for themselves on the text on a particular issue.

CL: And do you think that's one of the important parts of the seminar?

Duncan: I do. I also have a bad conscience about it. I mean, people do just use group work when they're at the end of their tether, to be quite frank. Just because it takes the onus off them for ten minutes or so. And I do think I do it for that reason. I do think it can be very productive. That's a bad reason for doing it, I'm saying this a lot this morning, there are good reasons for doing it as well, and the two do coincide and I think group work is a good idea. My problem with group work is that sometimes I think I'm doing it too often, that there comes a moment in every seminar when I distribute a text and get people to work in groups on a particular problem. And it becomes a bit samey and a bit stereotyped, that everyone sort of feels the format is going to be the same each week.

CL: Interesting. I found that when I was doing the groupwork that sometimes it depended on who you were working with and whether you had an idea you really wanted to talk about. So if I had something I wanted to say or somebody else did, that was great. I think once or twice I was with somebody else who didn't have so much to say.

Duncan: Yes. I think it does depend a lot on the students' ability and their cooperation. I mean there are some students in these classes who don't have the social skills or don't have the interest or haven't done the reading, and if you have any of those issues then it becomes very hard for them to talk.

CL: I did find it mostly very productive.

Duncan: Yes. Um.

The change in my positioning within this exchange is significant. My first response is a fairly standard prompt to get Duncan to elaborate his thoughts on the topic. At this point my position can be uncomplicatedly identified as that of researcher, eliciting information from my participant. Duncan's elicited account foregrounds some of his doubts about his use of group-work, 'sometimes I think 
I'm doing it too often', 'it becomes a bit samey'. This in turn prompted my own reflection on my experience of group-work in Duncan's classes, and I appeared to confirm his equivocal position, saying, 'sometimes it depended on who you were working with ... once or twice I was with somebody else who didn't have much to say'. Here I seem to have shifted into a more embedded position, reflecting on my own responses as participant, rather than as researcher. My final comment was, as I remember it, an attempt to retrieve an apparent complicity in denigrating group-work, and thus, although poorly articulated, represents another shift in my position, from participant to educator, a professional with views on the effectiveness of certain teaching practices.

What this account suggests is the discontinuities within my subjective position. My identifications as researcher, participant and educator pull me in different directions, but my articulation of these contrasting positions can be seen as a mechanism to unify, rather than repress, the conflicting fragments. Just as metaphor constitutes a relationship of association through the substitution of one word for another, the substitutions within my interventions here - of researcher, with participant, and finally with educator - can be seen as constructing an association between the conflicting aspects of my subjectivity, in an uncomfortable attempt to maintain all three within one coherent identity.

This chain of metaphorical associations was initiated, perhaps, in our earlier conversations about Duncan's teaching. Of the tutors who took part in the research, Duncan was the one who most explicitly used our discussions to reflect on his practice. In our initial meeting, before I began my observations, he talked about some of his concerns: his awareness, he said, that he could learn strategies to improve his teaching; his ambition 'to be the sort of teacher who knows all his students'; and his frustrations that the large classes he was working with made this difficult. He also talked analytically about changes he had made to the American Literature module as a response to students' lack of background in the necessary history, which he did not dismiss as ignorance, but recognized as an understandable contingency: 'why should they know it?' Duncan also described previous discussions that had helped him to reflect on his teaching: when he had felt frustrated at students' lack of interest in a particular text, for example, his mother had reminded him that he too had found the text dull when he had read it as an undergraduate. These references to his teaching, occasionally articulated as an explicit request for my views, as, perhaps, someone perceived to specialize in education, gave me the impression that Duncan interpreted my research as an opportunity to reflect on his own classroom practice. So it may be possible to interpret my final intervention as an attempt to fulfill the role that I interpreted Duncan as demanding: responding to his conception of the research as contributing to his development as a teacher by offering my (non) expert view on the productivity of group work.

Thus we can trace a chain of signification from Duncan's reflections on his teaching to my disjointed interventions in the exchange about group work. The 
metonymic connections between Duncan's expectations and my positioning as an educator cut across my more researcherly interventions, constituting an implicit comparison between the two roles that replicates the structure of metaphor. Whether my projections of Duncan's expectations were accurate or not is in some sense irrelevant. What is more relevant is the extent to which the metaphorical substitution was able to evoke an association between researcher and educator either within the interview, or, potentially, later on, in the analysis.

Within the interview Duncan's slightly imponderable response, 'yes, um', suggests that, perhaps, my intervention had not evoked a considered, educationalist-like evaluation of the role of group work in his classes. However, the duality in my position can also be identified in the written analysis of the research. I didn't explicitly analyse this part of our conversation within the thesis, but, perhaps in response to the exchange, I did insert a comment on the role of group-work in to the chapter on the American Literature classes:

Small group work helps students to generate and experiment with ideas and also provides an opportunity for discussion for students who may not feel so comfortable speaking in front of the whole class. As a result, it inevitably has the effect of producing more positions, more time and more access to ideas, from which students can speak. (Lapping, 2004, p. 193)

This objectifying claim, made as an aside, about the benefits of group work was based on my general experience as a teacher, rather than an academic expertise in the field of teaching and learning. It continues the uncomfortable attempt to unify contrasting subject positions, which has, I think, some ethical implications.

The ambiguity over my identity, in this instance, may, initially, be seen as a logic of difference, recognizing and responding to Duncan's concern to reflect on his teaching, which connects, metonymically, with the part of my research that derives from an interest in teaching and inclusion. However, the introduction of my specific views on the role of group work and my attempt to impose this view can be seen as a logic of equivalence, a move to subsume the differential features of Duncan's position. Although in this case it seems likely that the metaphorical substitution failed to obliterate or exclude other signifiers, this kind of move may be felt as a violent or unexpected assault. It has parallels, I believe, with the imposition of any external interpretive frame in the analysis of data, though I am thinking particularly of my own analysis of gender through the frame of Lacanian theory (Lapping, 2004, 2006), and of the omissions this kind of analysis enacts. The metaphorical substitution of a perceived to be uncritical researcher in the field with a theoretically informed author in the process of analysis is one that introduces a variety of ethical quandaries.

This example, then, illustrates both the interweaving of metonymic and metaphoric chains of signification within an interaction in the field, and also the way that metaphorical substitutions, in covering over gaps and discontinuities, 
may enact ethically significant exclusions, obscuring aspects of the field and differential subjective features of research participants.

Conclusions: interpretation, ethics and subjectivity

The description of the production of meaning across the contexts of field, analysis and writing as working through the discursive mechanisms of metaphor and metonymy has several effects. Primarily it disrupts the boundaries of each of these settings, foregrounding traces and associations that reveal the interdependency and incompleteness of both embedded experience and analytical writing. The clarification of these interconnections, I have suggested, may also help us to take fuller account of the selections and omissions we produce, in our interactions with participants and also in the fixing of meanings within our writing. The consideration of written analysis in particular may draw our attention to the closing down of meanings inherent to academic argument.

This article itself constitutes a signifier with Lacan's two modes of evocation. Its metonymic logic identifies similarities between my own work and that of Hey, Laclau and Mouffe and Lacan. This is a small, hegemonising move that attempts to restructure the field of education studies around psychoanalytically informed approaches to analysis in social research. The theoretical argument within the paper, in contrast, acts metaphorically to displace the more embodied and emotional aspects of the process of writing, which I have, nevertheless, attempted to retain at moments within the text (and in the addendum). I suspect, though, that whatever we hope to achieve through the representation of these embodied experiences, the act of (academic) writing purifies them into, at best, self-congratulatory 'reflexivity'. The text also re-articulates some of the interdependencies between my PhD thesis and the field, revealing omissions and displacements enacted in the original analysis, thus acting as a retrospective logic of difference. Perhaps the analysis of these mechanisms within the text can help us to identify our own part in a variety of strategic games that have ethical and political connotations.

The discussion also suggests ways in which the construction of meaning in field and analysis is analogous to verbal mechanisms of metaphor and metonymy. Instead of a word or image, fragments of conversations and written texts have been interpreted as working through similar discursive mechanisms in the production of meaning. This is not an original or, perhaps, a significant break from the original analysis of metaphor and metonymy within poetic or literary language, but it does replicate a shift from the application of these terms to describe words, sounds and images to a use closer to Laclau and Mouffe's political logics of equivalence and difference.

As a final reflection, it seems possible to think of metaphor and metonymy as mechanisms for the production of misrecognitions. They cover over gaps in discourse, presenting an illusion of wholeness, both at the level of the signifying system as a whole, and at the level of individual meanings and identities. The 
politics advocated by Laclau and Mouffe involves the disruption of these hegemonic misrecognitions, but also suggests that we make use of gaps within the symbolic in a radical political strategy that involves an active hegemonising of fields of discursivity. The tension between these two strategies evokes, again, the impossible tension Lacan describes within subjectivity:

This signifying game between metonymy and metaphor, up to and including the active edge that splits my desire between a refusal of the signifier and a lack of being, and links my fate to the question of my destiny, this game, in all its inexorable subtlety, is played until the match is called, there where I am not, because I cannot situate myself there. (Lacan, 1989, p. 183)

\section{Addendum}

When I had finished my research I sent a summary to all my participants. For the tutors, I also included a contents list, suggesting that they should ask if they would like me to send them any of the chapters. One of the tutors did not respond, and, when I bumped in to her some months later, apologized for not having read what I had sent her. Another tutor e-mailed to suggest we meet to chat about some of the points I had raised, which we did, and had a useful discussion. The third tutor responded very quickly, saying he was disappointed by some of the things I had said about his discipline, and offered to clarify some points with me. He also requested that I send him a chapter, and when I had done so, expressing my interest in his views, did not respond again.

Duncan was the most enthusiastic in his initial response to the summary. He emailed to say he thought it looked like an excellent thesis, and mentioned several points that he had thought particularly interesting. He also asked me to send him the chapter dealing with the American Literature classes. I was uncomfortable about sending the chapter, because I was aware that it included some interpretations of Duncan's practice that he might perceive as professionally or personally critical. Nevertheless, I sent the chapter, along with a badly worded email that, instead of explaining the possibility that he might not like what I had produced, simply re-asserted my admiration of his teaching. Duncan responded, thanking me for my compliments, and saying he would certainly read the chapter, when he was a little less busy, and that was sure he would have some comments when he had. He finished by saying he would be happy to help me again at some point in the future. I did not hear from him.

The silence from both of the participants who read chapters of the thesis is, in the scariest sense, imponderable. It raises serious ethical questions about the responsibility that we take on when we recontextualise participants' practice into the framework of our research. Our interpretations set up new chains of signification that have complicated and unpredictable ethical, emotional and political effects. 


\section{Bibliography}

Birch, M. and Miller, T. 2000, 'Encouraging Participation: Ethics and Responsiblities', in Mauthner et al. Ethics in Qualitative Research, London, Thousand Oaks, New Delhi: Sage Publications

Bourdieu, P. 1999, The Weight of the World, Polity Press

Bourdieu, P. 2000, Pascalian Meditations, Polity Press

Dunscombe, J. and Jessop, J. 2000, "'Doing Rapport" and the ethics of "Faking Friendship"', in Mauthner et al. Ethics in Qualitative Research, London, Thousand Oaks, New Delhi: Sage Publications

Finch, J. 1984, 'It's great to have someone to talk to": the ethics and politics of interviewing women", in Bell, C. and Roberts, H. Social Researching: Politics, Problems, Practice, London, Boston, Melbourne, Henley: Routledge and Kegan Paul

Gasche, R, 2004, 'How emptly can empty be? On the place of the universal', in Critchley, S. and Marchart, O, eds. Laclau: A Critical Reader, London and New York: Routledge

Hey, V. 1997. The Company She Keeps: An Ethnography of Girls' Friendships, Buckingham, Philadelphia: Open University Press

Hey, V. 2000, 'Troubling the Auto/biography of the Questions: Re/thinking 'rapport' and the Politics of Social Class in Feminist Participant Observation', in Walford, G. and Hudson, C. eds. Educational Ethnography, Vol. 3, pp. 161 - 183

Lacan, J. 1989, 'The Agency of the Letter in the Unconscious', pp. 161 - 197 in Ecrits: a selection, London and New York: Routledge

Laclau, E. and Mouffe, C. 2001, Hegemony and Socialist Strategy: Towards a Radical Democratic Politics, London, New York: Verso

Laclau, E. 1996, Emancipation(s), London, New York: Verso

Lapping, C. 2004, Discipline, Gender and Institution: an empirical study of in/exclusion in undergraduate American Literature and Political Thought classes, unpublished $\mathrm{PhD}$ thesis, University of London, Institute of Education

Lapping, C. 2005, 'Antagonism and overdetermination: the production of student positions in contrasting undergraduate disciplines and institutions in the UK', British Journal of Sociology of Education, Vol. 26, No. 5, pp. $657-671$

Lapping, C. 2006, 'Recodifications of academic positions and reiterations of desire: change but continuity in gendered subjectivities', Studies in Higher Education, Vol. 31, No. 4, pp. 423 - 437

Lapping, C. 2007, 'Interpreting 'resistance' sociologically: a reflection on the recontextualisation of psychoanalytic concepts into sociological analysis', forthcoming in Sociology

Ragland-Sullivan, E, 1986, Jacques Lacan and the Philosophy of Psychoanalysis, Urbana and Chicago: University of Illinois Press

Stavrakakis, Y. 1999, Lacan and the Political, London and New York: Routledge Walkerdine, V. 1982, 'A psychosemiotic approach to abstract thought', in Beveridge, M. Children Thinking Through Language, Suffolk: Edward Arnold 
Walderdine, V. 1988, The Mastery of Reason, London and New York: Routledge Zizek, S. 1989, The Sublime Object of Ideology, London, New York: Verso

\section{Acknowledgements}

Jill Brown, Jenny Parkes and Natasha Whiteman helped me greatly in the writing of this paper, as did Valerie Hey. I would also like to thank reviewers for their very helpful comments.

My PhD was funded by an ESRC doctoral studentship 